\title{
Structural and optical properties of zinc sulphide-polyvinyl alcohol (ZnS-PVA) nanocomposite thin films: effect of $\mathbf{Z n}$ source concentration
}

\author{
U BAISHYA and D SARKAR* \\ Department of Physics, Gauhati University, Guwahati 781 014, India
}

MS received 10 May 2010

\begin{abstract}
ZnS-PVA nanocomposite thin films are grown by chemical bath deposition (CBD) method by varying the concentration of zinc source. Formation of nanocrystalline hexagonal $\mathrm{ZnS}$ is confirmed by $\mathrm{X}$-ray diffraction. Hexagonal form is predominant at some lower concentration. The morphological properties of the films are determined by transmission electron microscope (TEM). The particle size as given by TEM indicates increase in particle size. Bandgap measured from UV-Visible transmission spectra shows a decreasing trend with decrease of $\mathrm{Zn}$ source concentration. Photoluminescence (PL) measurement showed blue emission centred at $417 \mathrm{~nm}$ and that the intensity decreases with decrease in $\mathrm{Zn}$ source concentration.
\end{abstract}

Keywords. Zinc sulphide; polyvinyl alcohol; nanocomposite; chemical bath deposition.

\section{Introduction}

During the last decade, research into nanocomposites has become quite popular in various fields of material science. Recently, fabrication of inorganic nanoparticles in polymer matrices has attracted much attention, because the combination of inorganic nanoparticles and a polymer provides a simple route to stable and processable composite materials, integrating the promising properties of both components (Pyun and Matyjaszewski 2001; Matras et al 2008). Semiconductor nanoparticles from the II-VI family have been applied to many different areas, including light emitting diodes, electroluminescent devices, photovoltaic devices, lasers, single electron transistors, as well as biological labeling and diagnostics (Brus 1986; $\mathrm{Hu}$ et al 2001; Kontsogeorgis et al 2001; Banerjee et al 2005; Hwang et al 2005; Manzoor et al 2005). In this context, $\mathrm{ZnS}$ nanocrystals are promising materials for wide range of applications. The nanocomposites may be formed either ex situ (Pyun and Matyjaszewski 2001) or in situ. We have adopted the latter. We have synthesized $\mathrm{ZnS}$ nanocrystals in the polymer (polyvinyl alcohol) (PVA) solution itself rather than preparing the nanocrystals first and then incorporating into the polymer, which has the possibility of development of heterogeneity in the composite. In particular, we have synthesized $\mathrm{ZnS}$ nanocrystals within PVA matrix and the composite film is deposited by 'chemical bath deposition' (CBD) method. Generally, in the reaction mixture the zinc and sulphur

\footnotetext{
*Author for correspondence (sarkardeepali@ rediffmail.com)
}

source materials are taken in equimolar ratio (Suyver et al 2001). We intend to investigate the properties of $\mathrm{ZnS}$ nanocrystals formed in PVA matrix by taking molar ratios of the two other than $1: 1$. We will be varying the $\mathrm{Zn}$ source concentration and keep the sulphur source concentration at a particular value. The composite thin films are studied for various analysis to observe the effect of zinc source concentration variation on various properties of these films.

\section{Experimental}

Materials used in the present synthesis were zinc acetate $\left[\mathrm{Zn}\left(\mathrm{CH}_{3} \mathrm{COO}\right)_{2}\right]$ as zinc source, sodium sulphide $\left(\mathrm{Na}_{2} \mathrm{~S}\right)$ as sulphur source, polyvinyl alcohol (PVA) as capping and dispersing agent, $\mathrm{NH}_{3}$ as reducing agent and deionized water as medium. Deposition of $\mathrm{ZnS}$ thin films on glass substrates was done by CBD method as detailed elsewhere (Guinier 1983) at a deposition temperature of $363 \mathrm{~K}$ as the film quality and adherence of the film to the substrate were reported to be the best at this temperature (Guinier 1983; Ghosh et al 2005). Fixing the $\mathrm{Na}_{2} \mathrm{~S}$ concentration constant at $2 \times 10^{-2} \mathrm{~mol}$, the zinc source concentrations were taken as $1 \cdot 0 \times 10^{-2}, 7 \cdot 5 \times 10^{-3}, 5 \cdot 0 \times 10^{-3}$, $2.5 \times 10^{-3} \mathrm{~mol}$ and the film deposition carried out in similar fashion. The deposited films were dried under dynamic vacuum for $48 \mathrm{~h}$ and kept under vacuum for different studies to be carried out. The films were characterized by XRD for structure, TEM for morphology and particle size, UV-Visible absorption spectroscopy for bandgap measurement and FTIR for assignment of $\mathrm{ZnS}-\mathrm{PVA}$ 
cross linking. Optical properties of the films were studied by measuring photoluminescence (PL) at room temperature at an excitation wavelength of $384 \mathrm{~nm}$.

XRD spectra were recorded by Philips X-pert pro diffraction (Model-PW 1830) with $\mathrm{CuK} \alpha(0 \cdot 154 \mathrm{~nm})$ radiation. TEM pictures were taken by JEM 100CXII, JEOL, Japan, at an accelerating voltage of $100 \mathrm{kV}$, UVVisible spectra were recorded by Hitachi U-3210 spectrometer, PL spectra were recorded by Hitachi F-2500, fluorescence spectrometer and FTIR spectra were recorded by Perkin Elmer Spectrum RXI FTIR system.

\section{Results and discussion}

\subsection{XRD study}

Figure 1 represents XRD of four different $\mathrm{ZnS}-\mathrm{PVA}$ composite films. The XRD patterns of the films show diffraction peaks at $2 \theta=28.5^{\circ}, 47.58^{\circ}$ and $56.39^{\circ}$. The highest intensity reflection peak is at $2 \theta=28 \cdot 5^{\circ}$ for $(002)$ plane, with two other small intensity peaks at $2 \theta=47.58^{\circ}$ and $56.39^{\circ}$ for $(110)$ and (112) planes, respectively indicating that (002) is the preferred direction (JCPDS no. 80-007). The peak position tallies with wurtzite structure of $\mathrm{ZnS}$ crystals (Qian et al 2000). Also, it is seen that the peak for (002) plane is most intense for the composite film with $\mathrm{Zn}^{++}$source concentration, $5 \cdot 0 \times 10^{-3}$ mol. This

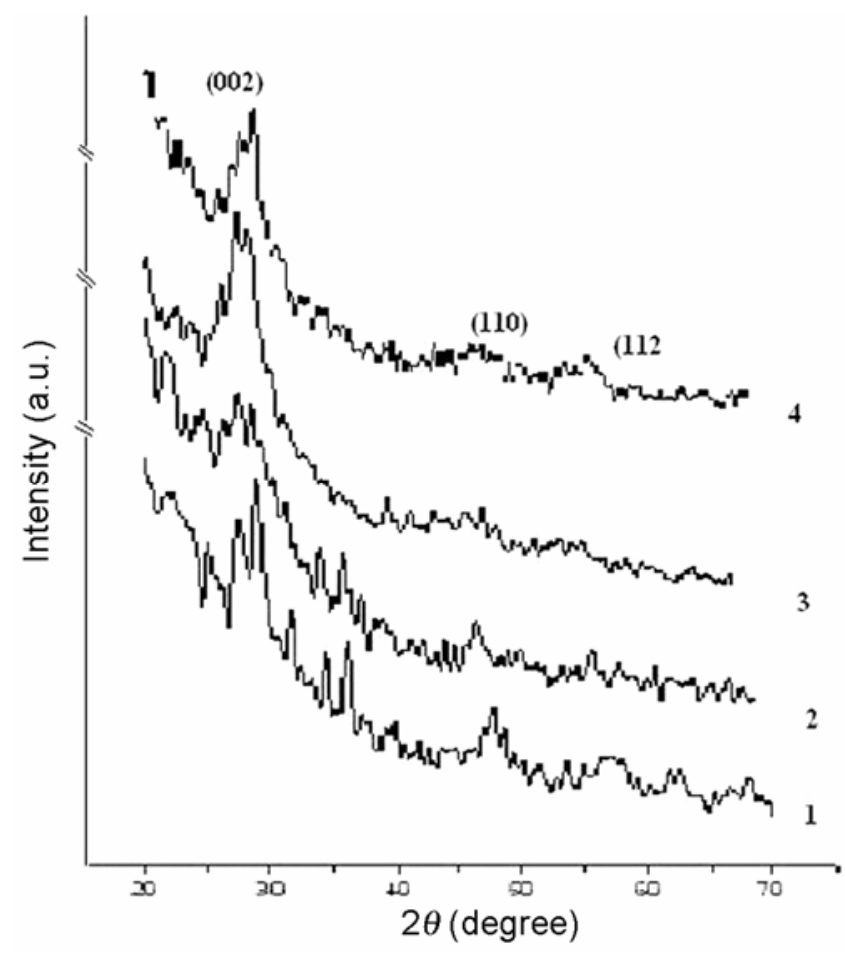

Figure 1. XRD patterns of $\mathrm{ZnS}$ nanocomposite films for different concentrations: (1) $0.01 \mathrm{~mol}$, (2) $0.0075 \mathrm{~mol}$, (3) $0.005 \mathrm{~mol}$ and (4) $0.0025 \mathrm{~mol}$. suggests maximum wurtzite structure for this particular film. This is followed by the one with $\mathrm{Zn}^{++}$concentration of $2.5 \times 10^{-3} \mathrm{~mol}$ where there may be mixing of wurtzite and cubic pseudomorphs.

\subsection{TEM study}

Figure 2 shows TEM pictures of $\mathrm{ZnS}$ thin films. From the micrographs it is clear that $\mathrm{ZnS}$ grains are not uniformly distributed. It is observed that grain sizes are not of much uniformity. The average grain size estimated from the histograms of frequency of occurrence vs particles size is found to vary from $20-40 \mathrm{~nm}$ and it is found to increase gradually as the $\mathrm{Zn}$ source concentration decreases. Also, with decrease in $\mathrm{Zn}$ source concentration to $5 \cdot 0 \times 10^{-3} \mathrm{~mol}$, the TEM picture shows almost total number of pseudomorphs as hexagonal, i.e. wurtzite structure. This is in conformity with the results of XRD analysis. Again, for the $\mathrm{Zn}^{++}$concentration of $2.5 \times 10^{-3}$ mol there is decrease of hexagonal pattern, again in conformity with XRD results. Further, for concentration of $1.0 \times 10^{-2}$ and $7 \cdot 5 \times 10^{-3} \mathrm{~mol}$, no particular shape could be identified.

\section{$3.3 U V$-Visible spectra}

In figure 3(a) we show the UV-Visible absorption spectra. The fundamental absorption which corresponds to the transition from valence band to conduction band can be used to determine the bandgap of the material. The relation between absorption coefficient $(\alpha)$ and photon energy $(h v)$ can be written as (Ghosh et al 2005):

$$
\alpha=\frac{A\left(h v-E_{\mathrm{g}}\right)^{n}}{h v},
$$

where $A$ is a constant, $E_{\mathrm{g}}$ the bandgap of the material and $n$ the exponent which depends on the type of transition (Hwang et al 2005) that occurred. The values of $n$ for direct allowed, indirect allowed and direct forbidden transitions are $n=1 / 2,2$ and $3 / 2$, respectively. To determine possible transitions, $(\alpha h v)^{1 / n}$ vs $h v$ can be plotted to give corresponding bandgap by extrapolating the straight line portion of the graph on the $h v$ axis to $\alpha=0$. Absorption coefficient $(\alpha)$ can be calculated by the relation

$$
\alpha=\frac{1}{d} \ln (1 / T),
$$

where $d$ is the thickness of films which is 1800-1900 $\AA$ in our case. We plotted $(\alpha h v)^{2}$ vs $h v$, i.e. for $n=1 / 2$ or for direct allowed transition. Plots for various films with varying concentrations of $\mathrm{Zn}$ source are shown in figure 3(b). Bandgap obtained from these plots are obviously the direct bandgap (Brus 1986). It is found that the bandgap increases from 3.4 to $3.8 \mathrm{eV}$ as the particle size decreases with increase in $\mathrm{Zn}$ source concentration. 

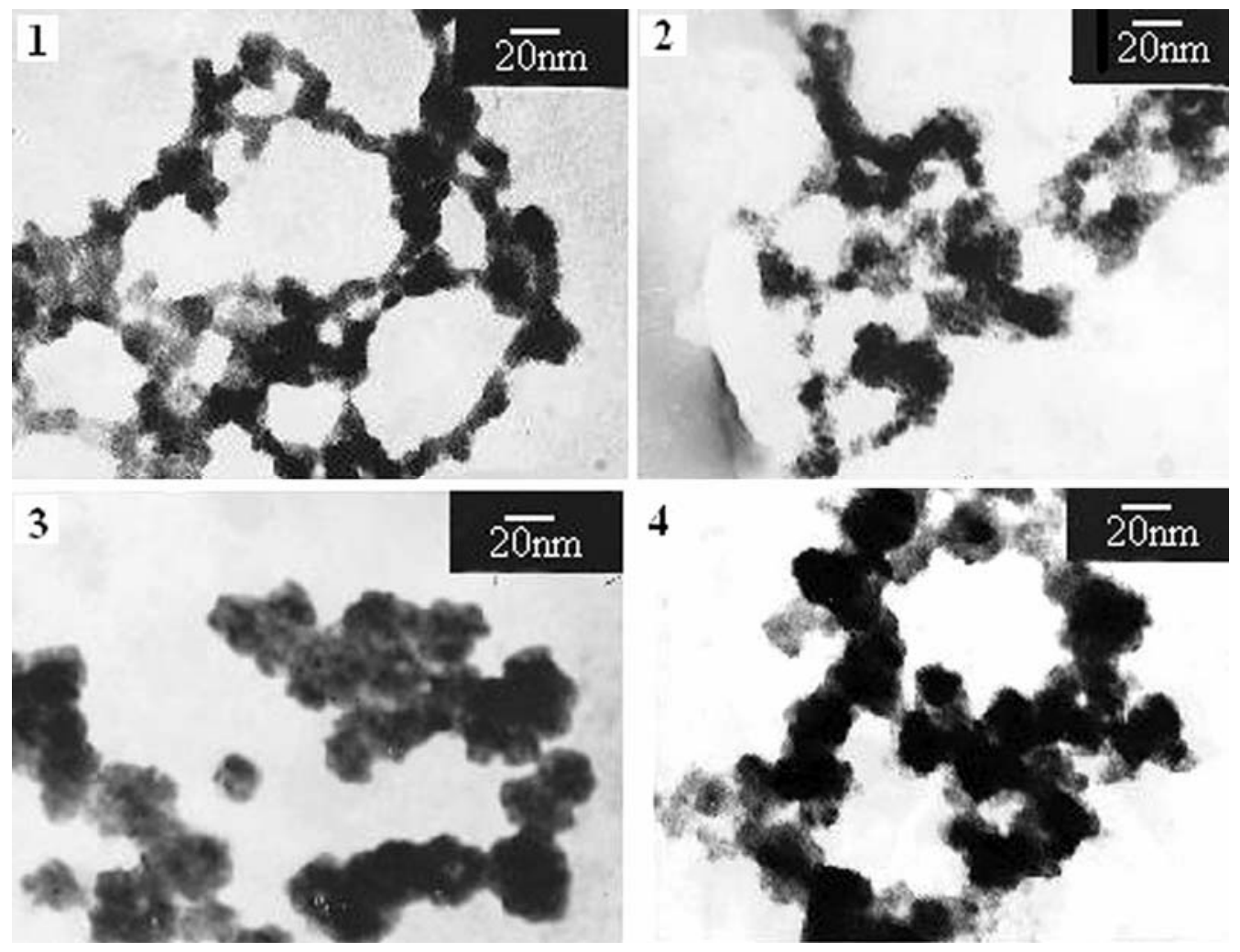

Figure 2. HRTEM micrographs of $\mathrm{ZnS}$ nanocomposite thin films for concentrations (1) $0.01 \mathrm{~mol}$, (2) $0.0075 \mathrm{~mol}$, (3) $0.005 \mathrm{~mol}$ and (4) $0.0025 \mathrm{~mol}$.
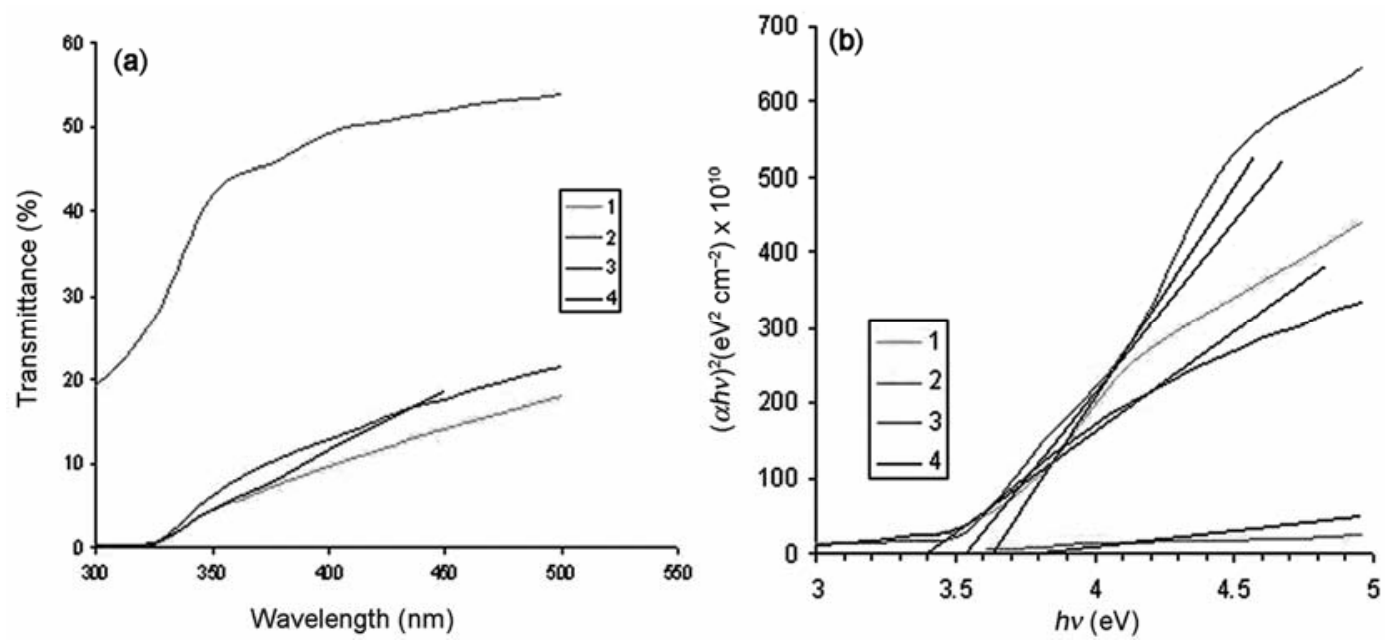

Figure 3. (a) Transmittance vs wavelength plot of $\mathrm{ZnS}$ thin film for concentrations (1) $0.01 \mathrm{~mol}$, (2) $0.0075 \mathrm{~mol}$, (3) $0.005 \mathrm{~mol}$ and (4) $0.0025 \mathrm{~mol}$ and (b) plot to determine direct bandgap of $\mathrm{ZnS}$ thin films for concentrations (1) $0.01 \mathrm{~mol}$, (2) $0.0075 \mathrm{~mol}$, (3) $0.005 \mathrm{~mol}$ and (4) $0.0025 \mathrm{~mol}$.

\subsection{FTIR study}

IR spectra of $\mathrm{ZnS}$ nanoparticles for different concentration of zinc source are shown in figure 4. IR peaks are assigned to the sample at room temperature. The IR spectra showed a peak at $1643.8 \mathrm{~cm}^{-1}$, representing the nitrogen-oxygen interaction. Bands around 900-
$1500 \mathrm{~cm}^{-1}$ are due to oxygen stretching and banding frequency. Weak additional bands were observed at 922.3 and $843.8 \mathrm{~cm}^{-1}$. These modes indicate the presence of resonance interaction between vibrational modes of sulphide ions in the crystal (Sooklal et al 1996). The peak at $620.4 \mathrm{~cm}^{-1}$ is assigned to $\mathrm{ZnS}$ band (i.e. corresponding to sulphides). 


\subsection{Photoluminescence (PL) study}

Optical property of the films is measured by PL study. PL spectra measured at room temperature of $\mathrm{ZnS}-\mathrm{PVA}$ nanocomposite thin films of various concentration ratios are shown in figure 5. In all the measurements, the excitation wavelength was $384 \mathrm{~nm}$. These plots contain three peaks centred at 411-417, 433·5-435.5 and 465.5-472 nm. PL spectra show both narrow and broad peaks for all these ratios. Appearance of these peaks in this region is due to the presence of sulphur vacancies in the lattice (Beeker and Bard 1983; Rabani 1989; Dhas et al 1999). This emission results from the recombination of photo generated charge carriers in shallow traps (Pyun and Matyjaszewski 2001; Manzoor et al 2005). It is also observed from PL spectra that the intensities of the peaks gradually decrease as the $\mathrm{Zn}$ source concentration decreases only with one exception for the $\mathrm{Zn}^{++}$concentra-

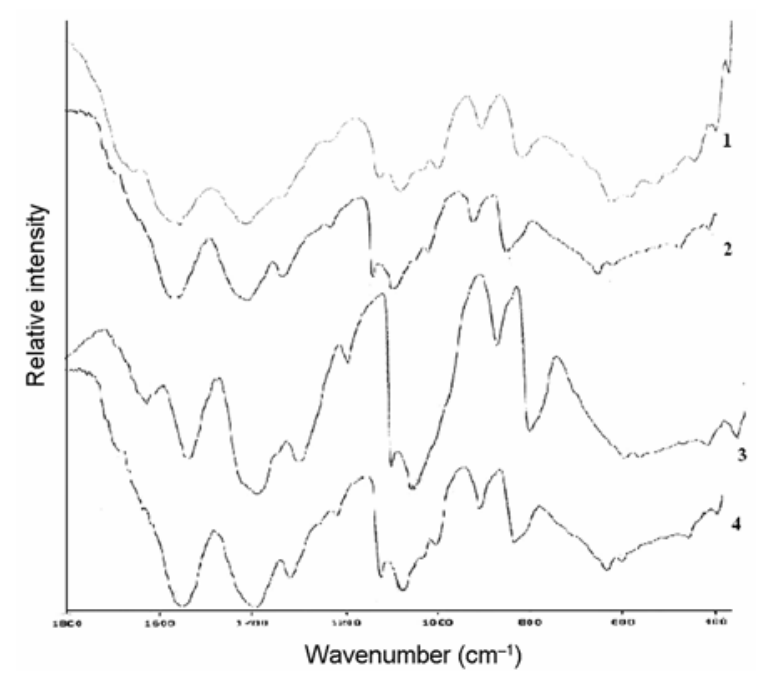

Figure 4. IR spectra of $\mathrm{ZnS}$ nanoparticle for concentrations (1) $0.01 \mathrm{~mol}$, (2) $0.0075 \mathrm{~mol}$, (3) $0.005 \mathrm{~mol}$ and (4) $0.0025 \mathrm{~mol}$.

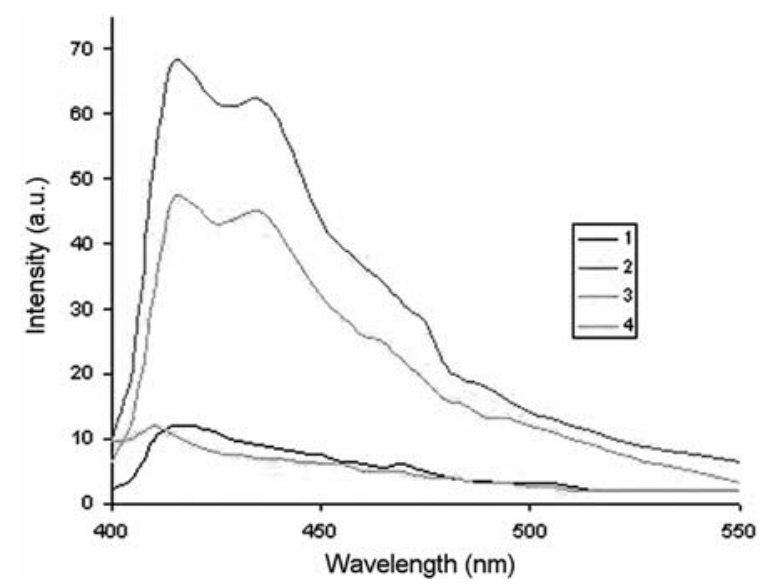

Figure 5. PL spectra of $\mathrm{ZnS}-\mathrm{PVA}$ thin films for concentrations (1) $0.01 \mathrm{~mol}$, (2) $0.0075 \mathrm{~mol}$, (3) 0.005 and (4) $0.0025 \mathrm{~mol}$. tion of $1.0 \times 10^{-2} \mathrm{~mol}$, which shows very less intensity. This may have some possible connection with the featureless picture of the grains as depicted by TEM.

\section{Conclusions}

There is significant change in various properties of $\mathrm{ZnS}-$ PVA nanocomposite film on changing the $\mathrm{Zn}$ source concentration in the reaction mixture. The nanograins show near total wurtzite structure for one particular concentration of $\mathrm{Zn}^{++}$. Also the changes are mostly systematic. With decrease in $\mathrm{Zn}$ concentration, the particle size is found to increase, whereas the bandgap for direct optical transition decreases. Further, with decrease in concentration, we observed decrease in PL intensity of the peaks.

\section{Acknowledgement}

The authors would like to acknowledge Dr P K Baruah, Department of Chemistry, Gauhati University for UVVisible, PL and FTIR measurements, Dr S Karmakar, University Science Instrumentation Centre, Gauhati University, for XRD measurements and Regional Sophisticated Instrument Centre, NEHU, Shillong, for TEM measurements.

\section{References}

Brus L E 1986 J. Phys. Chem. 90525

Banerjee I J, Yu L and Sui H M 2005 Am. J. Chem. Soc. 127 1600

Beeker W G and Bard A J 1983 J. Phys. Chem. 937707

Dhas N A, Zaban A and Gedanken A 1999 Chem. Mater. 11 806

Ghosh P K, Mitra M K and Chattopadhyay K K 2005 Nanotecnology 16107

Guinier A 1983 X-ray diffraction, in Crystals, imperfect crystals and amorphous bodies (San Francisco: WH Freeman and Co.) Ch. 2

Hu J, Yang L, Manna L, Wang L and Alivisatos A 2001 Science 2922060

Hwang J, Oh M O, Kim I, Lee J K and Ha C S 2005 Curr. Appl. Phys. 531

Kontsogeorgis D C, Mastoo E A, Cranton W M and Trmas C B 2001 Thin Solid Films 31383

Manzoor K, Vadera S R, Kumar N and Kutty J R N 2005 Appl. Phys. Lett. 84284

Matras K, Bredol M, Szatkowski A, Sakhno O, Stumpe J and Bogdal D 2008 Mol. Cryst. Liq. Cryst. 48528

Pyun J and Matyjaszewski K 2001 Chem. Mater. 132436

Qian X F, Yin J, Guo X X, Yang Y F, Zku Z K and Lu J 2000 J. Mater. Sci. Lett. 192215

Rabani J 1989 J. Phys. Chem. 937707

Sooklal K, Cullum B S, Angel S M and Murphy C J 1996 J. Phys. Chem. 1004551

Suyver J F, Weister S F, Kelly J J and Meijerink A 2001 Nano Lett. 1429 